\title{
Endemism and diversity of small mammals along two neighboring Bornean mountains
}

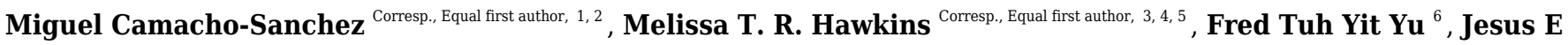 \\ Maldonado $^{3}$, Jennifer A Leonard ${ }^{1}$ \\ ${ }^{1}$ Conservation and Evolutionary Genetics Group, Doñana Biological Station (EBD-CSIC), Sevilla, Spain \\ 2 CiBIO - Centro de Investigação em Biodiversidade e Recursos Genéticos da Universidade do Porto, Vairão, Portugal \\ ${ }^{3}$ Center for Conservation Genomics, Smithsonian Conservation Biology Institute, National Zoological Park, Washington DC, United States \\ 4 Department of Biological Sciences, Humboldt State University, Arcata, California, United States \\ 5 Division of Mammals, National Museum of Natural History, Washington DC, United States \\ 6 Sabah Parks, Kota Kinabalu, Sabah, Malaysia \\ Corresponding Authors: Miguel Camacho-Sanchez, Melissa T. R. Hawkins \\ Email address: miguelcamachosanchez@gmail.com, Melissa.hawkins@humboldt.edu
}

Mountains offer replicated units with large biotic and abiotic gradients in a reduced spatial scale. This transforms them into well-suited scenarios to evaluate biogeographic theories. Mountain biogeography is a hot topic of research and many theories have been proposed to describe the changes in biodiversity with elevation. Geometric constraints, which predict the highest diversity to occur in mid-elevations, have been a focal part of this discussion. Despite this, there is no general theory to explain these patterns, probably because of the interaction among different predictors with the local effects of historical factors. We characterize the diversity of small non-volant mammals across the elevational gradient on Mount (Mt.) Kinabalu (4,095 m) and Mt. Tambuyukon (2,579 m), two neighboring mountains in Borneo, Malaysia. We documented a decrease in species richness with elevation which deviates from expectations of the geometric constraints and suggests that spatial factors (eg. larger diversity in larger areas) are important. The lowland small mammal community was replaced in higher elevations (from above $\sim 1900$ $\mathrm{m}$ ) with montane communities consisting mainly of high elevation Borneo endemics. The positive correlation we find between elevation and endemism is concordant with a hypothesis that predicts higher endemism with topographical isolation. This supports lineage history and geographic history could be important drivers of species diversity in this region. 


\section{Endemism and diversity of small mammals along two neighboring Bornean mountains}

3 Miguel Camacho-Sanchez ${ }^{1,2}$, Melissa T.R. Hawkins ${ }^{3,4,5}$, Fred Tuh Yit Yuh ${ }^{6}$, Jesús E.

4 Maldonado $^{3}$, Jennifer A. Leonard ${ }^{1}$

$5{ }^{1}$ Conservation and Evolutionary Genetics Group, Doñana Biological Station (EBD-CSIC),

6 Sevilla, Spain

$7 \quad{ }^{2} \mathrm{CiBIO}$ - Centro de Investigação em Biodiversidade e Recursos Genéticos da Universidade do

8 Porto, Vairão, Portugal

$9{ }^{3}$ Center for Conservation Genomics, Smithsonian Conservation Biology Institute, National

10 Zoological Park, Washington DC, United States

$11{ }^{4}$ Department of Biological Sciences, Humboldt State University, Arcata, California, United

12 States

13 5ivision of Mammals, National Museum of Natural History, Washington DC, United States

14 Sabah Parks, Kota Kinabalu, Sabah, Malaysia

15

16 Corresponding author:

17 Miguel Camacho-Sanchez

18 Email address: miguelcamachosanchez@gmail.com 


\section{Abstract}

21 Mountains offer replicated units with large biotic and abiotic gradients in a reduced spatial scale.

22 This transforms them into well-suited scenarios to evaluate biogeographic theories. Mountain

23 biogeography is a hot topic of research and many theories have been proposed to describe the

24 changes in biodiversity with elevation. Geometric constraints, which predict the highest diversity

25 to occur in mid-elevations, have been a focal part of this discussion. Despite this, there is no

26 general theory to explain these patterns, probably because of the interaction among different

27 predictors with the local effects of historical factors. We characterize the diversity of small non-

28 volant mammals across the elevational gradient on Mount (Mt.) Kinabalu (4,095 m) and Mt.

29 Tambuyukon (2,579 m), two neighboring mountains in Borneo, Malaysia. We documented a

30 decrease in species richness with elevation which deviates from expectations of the geometric

31 constraints and suggests that spatial factors (eg. larger diversity in larger areas) are important.

32 The lowland small mammal community was replaced in higher elevations (from above $\sim 1900 \mathrm{~m}$ )

33 with montane communities consisting mainly of high elevation Borneo endemics. The positive

34 correlation we find between elevation and endemism is concordant with a hypothesis that

35 predicts higher endemism with topographical isolation. This supports lineage history and

36 geographic history could be important drivers of species diversity in this region.

37 Keywords: Mt. Kinabalu, Mt. Tambuyukon, Shannon index, Sundaland, elevational gradient 


\section{Introduction}

40 Understanding the mechanisms that are responsible for shapping patterns of biodiversity across

41 geography has been an important driver of biological research (eg. Wallace, 1869; Heaney, 1986;

42 Rosenzweig, 1995; Lomolino et al., 2010). Mountains are valuable natural experiments that

43 allow researchers to test biogeoraphical hypotheses for these reasons: (1) they have limited

44 confounding variation across historical and ecological conditions, (2) they are discrete units to

45 study and (3) they offer replicated gradients for factors (climatic, spatial, ecological) that have

46 been central for research in biogeography (Brown, 2001). Numerous studies have sought to

47 explain the change of alpha diversity across elevation for diverse taxonomic groups (eg. Rahbek,

48 1995; Patterson \& Stotz, 1998; Heaney, 2001; Chen et al., 2006; Kluge, Kessler \& Dunn, 2006).

49 Previous research on diversity gradients on mountains has focused on the relationship between

50 diversity gradients on mountains with temperature and precipitation, primary productivity, area,

51 isolation, and geometric constraints. However, the effects of abiotic predictors on mountains are

52 inconsistent across studies (eg. Rahbek, 1995; Patterson \& Stotz, 1998; Heaney, 2001; Chen et

53 al., 2006; Kluge, Kessler \& Dunn, 2006), and to date, no uniform theory explains mammalian

54 diversity gradients on mountains (Brown, 2001; Lomolino, 2001; Heaney, 2001; Stevens, Rowe

55 \& Badgley, 2019).

Geometric constraints stand out from the former predictors as the most recurrent

57 explanation for diversity gradients on mountains across many systems (Rahbek, 1995; Fu et al.,

58 2006; Kluge, Kessler \& Dunn, 2006; Rowe, 2009). Geometric constraints predict that the overlap

59 of species' ranges on a constrained area causes species richness to be higher at the center of this

60 area (Colwell \& Lees, 2000). Translated to mountains, geometric constraints predict a higher

61 diversity at mid-elevations (mid-elevation bulge) caused by the overlap of species ranges with 
62 midpoints at different elevations. This phenomenon is often referred to as Mid-Domain Effect

63 (MDE). In mammals, a MDE has been reported across different mountain ranges, but it is not a

64 global pattern (Rickart, 2001; Heaney, 2001; Nor, 2001; Li, Song \& Zeng, 2003; McCain, 2004,

65 2005; Rowe, 2009; Rowe, Heaney \& Rickart, 2015; Hu et al., 2017).

66 The history of lineage and place can profoundly influence current patterns of diversity on

67 mountains (Brown, 2001; Lomolino, 2001; Stevens, Rowe \& Badgley, 2019). These effects of

68 history vary from mountain system and taxa, which has hampered the consolidation of a theory

69 to explain species richness on mountain gradients (Brown, 2001). On mountaintops, (1) more

70 geographical isolation should favor speciation and restrict processes of dispersal and

71 colonization, and (2) species richness should decline as a consequence of higher extinction

72 caused by generally smaller areas associated with higher elevation bands (Brown, 2001;

73 Lomolino, 2001). This, in turn, should lead to fewer species but higher endemism on

74 mountaintops. A recent worldwide review on plant endemism on mountains by Steinbauer et al.

75 (2016) found a clear correlation of peak isolation with increased endemism in mountaintops.

76 They suggested the coupling of historical climate changes with topography as a "pump" for

77 montane endemism (Steinbauer et al., 2016). For mammals, there is growing evidence that

78 endemism increases with elevation (Sánchez-Cordero, 2001; Heaney, 2001; Swenson et al.,

79 2012; Chen et al., 2017), but this data is often descriptive and lacks statistical testing.

80 Here we surveyed non-volant small mammals across elevational gradients on two tropical

81 mountains from the same range, Mt. Kinabalu and Mt. Tambuyukon, in northern Borneo. Mt.

82 Kinabalu $(4,095 \mathrm{~m})$ is the tallest mountain in Sundaland, a tropical hotspot of biodiversity

83 (Myers et al., 2000). A number of taxa have been surveyed across large elevational transects on

84 this mountain: moths (Beck \& Chey, 2008), ants (Brühl, Mohamed \& Linsenmair, 1999; Malsch 
85 et al., 2008), plants (Kitayama, 1992; Aiba \& Kitayama, 1999; Aiba, Takyu \& Kitayama, 2005;

86 Grytnes \& Beaman, 2006; Grytnes et al., 2008), oribatid mites (Hasegawa, Ito \& Kitayama,

87 2006), snails (Liew, Schilthuizen \& bin Lakim, 2010) and small mammals (Nor, 2001). These

88 studies have recovered either a decline in diversity with elevation, which seems to fit a global

89 pattern (Rahbek, 1995) or a mid-domain effect (MDE). To date, Nor's (2001) survey is the most

90 comprehensive dataset of non-volant small mammals on Mt. Kinabalu. It describes a clear MDE,

91 although the number of species he reports in the lowest elevation was unexpectedly low (only

92 five species), compared to the maximum of approximately 35 non-volant small mammals that are

93 known to be distributed in the lowland forests of Borneo (Nor, 2001; Payne et al., 2007). Thus,

94 there could be a strong bias in the interpretations caused by incomplete sampling of the lowest

95 elevation (Rahbek, 1995; Lomolino, 2001). Furthermore, Mt. Kinabalu is a hotspot of endemism

96 for many mountain lineages (Payne et al., 2007; van der Ent, 2013; Merckx et al., 2015). The

97 montane conditions in the upper slopes of Mt. Kinabalu are unique in Sundaland. Similar

98 conditions are only partially found on a handful of other peaks in Borneo (ie. upper montane

99 forest in Mt. Tambuyukon, 2,579 m, Wood \& van der Ent, 2012; Mt. Trusmadi, 2,642 m,

100 Kitayama et al., 1993; Mt. Murud, 2,423 m, Beaman \& Anderson, 1997; and Mt. Mulu, 2,376 m,

101 Collins, 1980) and on several peaks in Sumatra (Laumonier, 1997).

102 This study aimed to describe the effects of (1) the MDE on alpha diversity (species

103 richness) and (2) mountain endemics on beta diversity (change in the composition of the

104 community), for small non-volant mammals along the elevational gradient on Mt. Kinabalu and

105 Mt. Tambuyukon. We hypothesized that alpha diversity should decrease with elevation

106 coinciding with less available area and less complex habitat heterogeneity, while greater

107 endemism on higher elevational bands should correlate with the particular isolation of Mt. 
108 Kinabalu in Sundaland. For this purpose, we characterized the small mammal diversity along the

109 elevational gradient on Mt. Kinabalu and Mt. Tambuyukon. The raw data is fully accessible and

110 all analyses and figures are reproducible (DOI: 10.5281/zenodo.3341178).

\section{Materials \& Methods}

112 Study sites

113 Mt. Kinabalu and Mt. Tambuyukon are two neighboring peaks inside Kinabalu National Park in

114 the Malaysian state of Sabah, Borneo (Figure 1). This park covers 764 square kilometers. Mt.

115 Kinabalu is the tallest peak in Borneo at 4,095 $\mathrm{m}$ and is home to thousands of endemic plant and

116 animal species (Payne et al., 2007; van der Ent, 2013). Mt. Tambuyukon (the $3^{\text {rd }}$ highest peak in

117 Borneo, 2,579 m; Figure 1), despite being only $18 \mathrm{~km}$ away, is far less scientifically explored.

118 The vegetation zones as described by Kitayama (1992) for Mt. Kinabalu have been used for

119 simplicity as well as for consistency with previous elevational surveys (Nor, 2001): lowland

120 (>1,200 m), lower montane (1,200-2,000 m), upper montane (2,000-2,800 m) and subalpine

$121(2,800-3,400 \mathrm{~m})$.

122 The lowland dipterocarp forest dominates both mountains from the lowest elevations up

123 to $1,200 \mathrm{~m}$. Above this elevation begins the lower montane oak forest of $10-25 \mathrm{~m}$ trees up to

124 around 1,800-1,900 m on both Mt. Kinabalu and Mt. Tambuyukon. On Mt. Tambuyukon at

$1251,440 \mathrm{~m}$ there is a sharp break to an ultramafic outcrop and the vegetation changes to a low

126 productivity forest with shorter trees. The mossy or cloud forest begins at around 2,000 $\mathrm{m}$ on

127 both mountains. This zone is usually immersed in clouds, moss covers most surfaces, and pitcher

128 plants (genus Nepenthes), epiphytes, orchids, and climbing bamboos are abundant. At 2,350 m

129 on Mt. Tambuyukon and 2,600 $\mathrm{m}$ on Mt. Kinabalu there is a fast transition to an open stunted

130 forest dominated by Dacrydium and Leptospermum species. At these elevations, the vegetation 
131 develops a sclerophyllous and microphyllous syndrome. At 2,800 m the subalpine vegetation

132 appears on Mt. Kinabalu, which is absent on Mt. Tambuyukon.

\section{Field survey}

134 Surveys were conducted in two consecutive field seasons along elevational gradients following

135 climbing trails along Mt. Tambuyukon and Mt. Kinabalu. We targeted small non-volant

136 mammals and further included opportunistic observations and data from trail cameras. Species

137 identification was performed according to Payne et al. (2007). During the first field season, we

138 surveyed Mt. Tambuyukon in June-August 2012. Surveys for the second field season were

139 conducted on select locations on Mt. Tambuyukon (to fill gaps in the first season sampling) and

140 along the full elevational gradient of Mt. Kinabalu in February-April 2013.

141 We set traps from $\sim 331-2,509 \mathrm{~m}$ on Mt. Tambuyukon, and from $503-3,466 \mathrm{~m}$ on Mt.

142 Kinabalu (Dataset S1). The taxa we expected in the small mammal trap surveys included

143 members of the families Soricidae (shrews), Erinaceidae (gymnures), Tupaiidae (treeshrews),

144 and rodents in the families Muridae (mice and rats) and Sciuridae (squirrels). Trapping was

145 conducted following ethical standards according to the guidelines of the American Society of

146 Mammalogists (Sikes et al., 2011). Animal care and use committees approved the protocols

147 (Smithsonian Institution, National Museum of Natural History, Proposal Number 2012-04 and

148 Estación Biológica de Doñana Proposal Number CGL2010-21524). Field research was approved

149 by Sabah Parks (TS/PTD/5/4 Jld. 45 (33) and TS/PTD/5/4 Jld. 47 (25)), the Economic Planning

150 Unit (100-24/1/299) and the Sabah Biodiversity Council (JKM/MBS.1000-2/2(104)).

151 Line transects were set at approximately every $400-600 \mathrm{~m}$ in elevation. On Mt.

152 Tambuyukon, transects were placed along the mountaineering trail markers (placed every 1

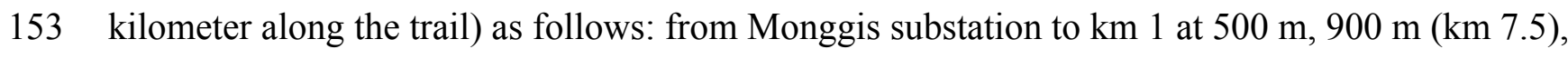


$1541,300 \mathrm{~m}(\mathrm{~km} \mathrm{10.3)}, 1,600 \mathrm{~m}(\mathrm{~km} \mathrm{11)}, 2,000 \mathrm{~m}(\mathrm{~km} \mathrm{12.6)}$ and 2,400 m (km 13.5). On Mt.

155 Kinabalu the 500 and $900 \mathrm{~m}$ transects were located at Poring Hot Springs from the entrance and

156 along the trail to the Langanan Waterfall. The next elevation transect for Mt. Kinabalu was set at

$157 \sim 1,500 \mathrm{~m}$ at the Park Headquarters, $\sim 2,200 \mathrm{~m}$ along the Timpohon mountaineering trail $(\mathrm{km} \mathrm{2,}$

158 Kamborangoh), 2,700 m (km 4, Layang-Layang), and 3,200 m (around Waras, Pendant hut, and

159 Panar Laban). For reporting results and data analysis, we hereafter refer to these locations as

160 "trapping locations". Each trapping location gathered the trap data from transects which could

161 span a distance of over $100 \mathrm{~m}$ up- or downhill (raw data in Dataset S1).

162 We set traps at approximately $5-10 \mathrm{~m}$ intervals for a total of around 40 traps per

163 transect. Trapping locations are shown in Figure 1. Collapsible Tomahawk live traps $(40 \mathrm{~cm}$

164 long), collapsible Sherman traps (two sizes used: $30 \mathrm{~cm}$ and $37 \mathrm{~cm}$ long), and local mesh-wire

165 box traps were used. We considered traps as 'close to the ground' if set below approximately $3 \mathrm{~m}$

166 off the ground. Most of these traps were directly set on the ground, while a small proportion was

167 set on branches or vines at the reach of the hand. We considered the 3-m threshold as reasonable

168 to describe the terrestrial small mammal community given the arboreal habits of many small

169 terrestrial Bornean mammals (Wells et al., 2004) and the high-complexity of the vegetation in

170 most transects. Any trap above that was considered 'arboreal'. A bait mixture (of varying

171 composition) consisting of bananas, coconuts, sweet potatoes, palm fruit and oil, vanilla extract,

172 and dried fish was placed in each trap. A small number of pitfall traps were distributed from 500

$173-2,000 \mathrm{~m}$ on Mt. Tambuyukon (number and distribution were limited by the substrate) (Table 1).

174 Each trapping location had a total of $2-4$ transects. The highest elevation had a lower

175 number of trap nights due to the smaller area available for placement of traps. Coordinates for

176 trapping locations were recorded using Garmin eTrex $^{\circledR}$ series and Garmin GPSmap 60CSx. The 
177 minimum number of trap nights was based on the saturation rates obtained from Nor (2001) at

178 approximately 300 trap nights. For every sampling location (elevation within mountain) the

179 cumulative trap-nights and species richness were calculated by adding the cumulative number of

180 species caught and trap-nights for each trap for each successive day from the date the trap was 181 set.

182 We set up 4 camera traps (Reconyx RapidFire RC55 ${ }^{\mathrm{TM}}$ cameras, and ScoutGuard HCO 183 cameras) along the mountaineering trail on Mt. Tambuyukon. Camera 1 was placed at $500 \mathrm{~m}$, at

184 the first-kilometer marker for the hiking trail. Cameras 2 and 3 were placed along the Kepuakan

185 River near km 8 and at approximately $900 \mathrm{~m}$. Camera 4 was placed at approximately 1,300 m

186 near km 10.5. No cameras were deployed along the Mt. Kinabalu trail due to a large number of

187 day hikers and mountain climbers.

188 Additionally, while on Mt. Tambuyukon we opportunistically recorded mammal

189 observations while walking to, from and along our trap lines, while setting cameras, or while in 190 our campsite.

191 Alpha diversity

192 Diversity index. We computed diversity indices for each trapping location. The

193 Community Ecology Package 'vegan' 2.5-5 (Dixon, 2003) in R 3.5.1 (R Development Core

194 Team, 2018) was used to calculate the Shannon diversity (H') and Simpson's diversity. Pielou's

195 evenness (J') was calculated as $\mathrm{J}^{\prime}=\mathrm{H}^{\prime} / \mathrm{H}_{\max }$, and species richness $(\mathrm{S})$ as the number of species.

196 We used the LOWESS smoother (stats::lowess function, in R) to visualize the change of these

197 indexes with elevation. The pattern of species richness across elevation in each mountain was

198 contrasted against the mid-domain effect using 'rangemodelR' 1.0.4 (Marathe, 2019) in R, as in

199 Wang \& Fang, 2012. We used the function range.shuffle which returns the pattern of species 
200 diversity under the mid-domain effect. The following arguments were used for computations: 50

$201 \mathrm{~m}$ as the interval to discretize species ranges and midpoints into elevational bands, soft

202 boundaries, and 5,000 repetitions.

203 Predictors of species richness. The relation between species richness and two predictors,

204 (1) elevation and (2) expectations under the MDE, were assessed in separate linear models with

205 mixed-effects (Laird \& Ware, 1982) using lme function from 'nlme' package 3.1-137 (Pinheiro

206 et al., 2018) in R. Model building and the evaluation of their fit was carried following the

207 recommendations in Harrison et al. (2018). In both models, we corrected for spatial

208 autocorrelation by including a term to account for the correlation structure built with

209 nlme::corSpatial function in R. This object contained the centroids of coordinates from all

210 animals trapped at a given location. Mountain was included as a random intercept. The fit of

211 these models was compared using likelihood ratio tests (King, 2010) against a null model that

212 excluded the fixed effect (Nickerson, 2000; Pinheiro \& Bates, 2006; Harrison et al., 2018).

213 Endemism. We quantified endemism at each trapping location as the proportion of

214 endemic species. This measure is robust to sampling bias and it is not overridden by local

215 diversity (Steinbauer et al., 2016). We defined endemic as only found in Borneo. Shrews were

216 excluded as we were not able to identify them to the species level. To visualize the change of

217 proportion of endemics with elevation we created a confidence envelope by resampling 1,000

218 times the species present at each trapping location. This same approach was used to visualize the

219 proportion of captures that belonged to endemic species across elevation. We evaluated the

220 contribution of elevation (predictor) to explaining the proportion of endemism (dependent

221 variable 1) and the proportion of captures (dependent variable 2) that corresponded to endemic

222 species. We used generalized models with mixed effects using a binomial family with logit link. 
223 Mountain was added as a random intercept. Model fitting was done using glmer function from

224 'Ime4' package 1.1-21 (Bates et al., 2015) in R. The fit of these models was compared using

225 likelihood ratio tests against a null model that excluded the fixed effect (Nickerson, 2000;

226 Pinheiro \& Bates, 2006).

227 Beta diversity

228 We calculated beta diversity for each mountain using a Sorensen-based dissimilarity

229 index $\left(\beta_{\mathrm{SOR}}\right)$ with its turnover $\left(\beta_{\mathrm{SIM}}\right)$ and nestedness $\left(\beta_{\mathrm{NES}}\right)$ components (Baselga, 2010). For

230 calculations we used function beta.multi, from package 'betapart' 1.3 (Baselga \& Orme, 2012) in

231 R. These calculations were also done pairwise between all trapping locations within the same

232 mountain using the function betapart::beta.pair. These distances were used for a cluster analysis

233 using neighbor-joining with (Saitou \& Nei, 1987) using ape::nj function in R to evaluate the

234 community similarity between mountains and elevations.

235 We estimated the contribution of endemics to $\beta_{\mathrm{SIM}}$ and $\beta_{\mathrm{NES}}$ components of beta

236 diversity. For each mountain, we removed endemic species from the dataset and recalculated

$237 \beta_{\mathrm{SIM}}$ and $\beta_{\mathrm{NES}}$ (hereafter referred to as $\beta_{\mathrm{SIM}-\text { end }}$ and $\beta_{\mathrm{NES}-\mathrm{end}}$ ). We created subsets of the data to

238 which these measures could be directly compared by randomly sub-sampling 5,000 times

239 without replacement, several species from the complete dataset equal to the non-endemics

240 present in that mountain. P-values were determined from the distributions of the permutated

241 values. 


\section{Results}

243 Field survey

244 The overall trapping success increased towards high elevation on both mountains. On Mt.

245 Tambuyukon, we trapped a total of 295 different individuals (not including recaptured animals)

246 from 21 different species (Dataset S1, Table S1) over 5,957 trap nights, for a total of 5.0\% trap

247 success (not including arboreal or pitfall trapping; Table 1). Trap success at each elevation

248 ranged from $2.1 \%$ at $1,600 \mathrm{~m}$ to $9.6 \%$ at $2,400 \mathrm{~m}$. One non-target capture of a carnivore, a

249 Kinabalu ferret-badger (Melogale everetti), was recorded. The trap success calculations were

250 done excluding pitfall traps and arboreal traps (due to inconsistent placement of traps). The use

251 of pitfall and arboreal traps was limited by the time necessary to set and check arboreal traps,

252 difficulty finding appropriate places to set pitfall traps and the high number of tourists on Mt.

253 Kinabalu, which limited the sites we could set traps to those out of sight of the trails. The

254 accumulation of species across trap nights varied across elevations, and appeared near saturation

255 in all trapping locations (Figure S1). A species of shrew, Suncus sp., was collected in a pitfall

256 trap, and a gray tree rat (Lenothrix canus) in an arboreal trap, bringing the total number of

257 species to 23.

258 On Mt. Kinabalu, we trapped a total of 20 species from 209 different individuals (Dataset

$259 \mathrm{~S} 1$; Table S1) over 2,022 trap nights, for an average trap success of 10.3\% (Table 1). The trap

260 success across elevations was much higher on Mt. Kinabalu, ranging from 5.6\% (at $900 \mathrm{~m}$ ), to

$261 \quad 15.4 \%$ (at 2,700 m) (Table 1). This overall higher capture rate resulted in species saturation with

262 a lower number of trap nights on Mt. Kinabalu than on Mt. Tambuyukon (Figure S1). 


\section{Species distribution}

264 The mountain treeshrew, Tupaia montana, was the most frequently caught species $(35.7 \%$ of all

265 catches) and it had a wide elevational distribution from $836-3,382 \mathrm{~m}$. The Bornean mountain

266 ground squirrel (Sundasciurus everetti, formerly Dremomys everetti; Hawkins et al. 2016), the

267 long-tailed giant rat (Leopoldamys sabanus), and Whitehead's spiny rat (Maxomys whiteheadi)

268 also had large elevational distributions on both mountains (Figure 2). The lowland $(<1,000 \mathrm{~m})$

269 terrestrial small mammal community was the most diverse with 19 species trapped. We captured

27016 species in the community associated with montane forest between 1,000 - 2,400 m and only 7

271 species at 2,400 $\mathrm{m}$ and above (Figure 2).

272 We captured a single shrew (Suncus sp.) after a trapping effort of 176 pitfall trap nights.

273 A less intensive arboreal trapping effort of 76 trap nights yielded seven individuals from six

274 small mammal species: Tupaia montana $(\mathrm{n}=2)$, Lenothrix canus $(\mathrm{n}=1)$, Callosciurus prevostii

$275(\mathrm{n}=1)$, Sundasciurus jentinki $(\mathrm{n}=1)$, Sundamys muelleri $(\mathrm{n}=1)$ and Tupaia minor $(\mathrm{n}=1)$.

276 Despite the smaller effort of arboreal trap nights, we still captured two species that were not

277 trapped elsewhere (Lenothrix canus and Sundasciurus jentinki). We used a threshold of three

278 meters off the ground to consider a trap arboreal. However, we also caught arboreal species in

279 ground traps or traps close to the ground $(<3 \mathrm{~m})$, including Chiropodomys pusillus, Callosciurus

280 prevostii and Tupaia minor.

281 We set 4 trail cameras on Mt. Tambuyukon to document larger mammals not targeted by

282 our traps. They documented an additional 8 species of mammals (Table 2; Figure S2). The

283 number of species captured by the cameras varied from one to five, with the camera at $500 \mathrm{~m}$

284 exhibiting the most diversity, both in number of species and number of independent visits (Table

285 2). They documented four species that were not documented in any other way. 
On Mt. Tambuyukon, several species were detected only through direct observation

287 (Table 3). Of these sightings many were documented only a single time, including the orangutan

288 (Pongo pygmaeus), the Bornean giant tufted ground squirrel (Reithrosciurus macrotis),

289 Whitehead's squirrel (Exilisciurus whiteheadii), and the bearded pig (Sus barbatus). The

290 Bornean gibbon (Hylobates muelleri) was heard singing on an almost daily basis, but only

291 directly observed a single time. The sambar deer (Rusa unicolor) was heard vocalizing once at

292 1,400 m. Only one observation was made of a carnivore, the Malay civet (Viverra tangalunga),

293 which was observed during a late night-walk. The visual observations increased the diversity of

294 species documented, especially for primates and tree squirrels.

\section{Alpha diversity}

296 Both mountains showed a similar pattern for alpha diversity indices across elevations (Figure 3;

297 Table S2). Species richness and Shannon diversity were maximum in low elevations and

298 decreased gradually towards high elevations. However, evenness was lowest at middle elevations

299 (U-shaped) (Figure 3). The high dominance of some species at middle elevations (e.g. mountain

300 treeshrew) leads the Shannon diversity to sink at around 1,500 $\mathrm{m}$ in both mountains. However,

301 Shannon diversity increases again towards the highest elevations due to the more even

302 occurrence of the species in the small mammal communities at these elevations, despite the

303 lower species richness (Figure 3). The species richness we report in low elevations for both

304 mountains are above the upper 97.5\% quantile of the expected richness expected under the

305 hypothesis of the mid-domain effect (Figure 3A).

306 We detected a significant negative relationship between species richness and elevation (

$\left.307 \chi_{1}^{2}=8.81, \mathrm{p}=0.003\right)$. However, species richness was not correlated with expected species

308 richness under the $\operatorname{MDE}\left(\chi_{1}^{2}=0.54, \mathrm{p}=0.46\right)$ (Figure 3). 
$310 \mathrm{df}=1, \mathrm{p}=0.005)$ and a greater proportion endemic species captured $\left(\chi^{2}=10.7, \mathrm{df}=1, \mathrm{p}=\right.$

$3110.001)$ (Figure 4).

312 Beta diversity

313 Variation in the species composition assemblages, or beta diversity, was very similar for

314 both mountains $\left(\beta_{\mathrm{SOR}}=0.77\right.$ on Mt. Kinabalu and $\beta_{\mathrm{SOR}}=0.74$ on Mt. Tambuyukon). Most of this

315 beta diversity derived from the turnover component $\left(\beta_{\mathrm{SIM}}=0.73\right.$ for Mt. Kinabalu and 0.65 for

316 Mt. Tambuyukon). The nestedness component was very low on both mountains $\left(\beta_{\mathrm{NES}}=0.04\right.$ for

317 Mt. Kinabalu and 0.09 for Mt. Tambuyukon) (Figure 5). This indicates that the assemblages at

318 different elevations are not the product of species loss from the richest assemblages. Instead, they

319 are singular assemblages with different species compositions. We found large dissimilarities in

320 the turnover component between pairwise locations within each mountain $\left(\beta_{\text {sim }}\right)$ associated with

$321<\sim 1900 \mathrm{~m}$ vs $>\sim 1900 \mathrm{~m}$ locations, compared to lower values within lowland or highland

322 locations (Tables S3). When removing endemic species from the dataset, $\beta_{\mathrm{NES}-\text { end }}$ increased and

$323 \beta_{\text {SIM-end }}$ decreased on both mountains (Figure 5). The permutations indicated that this decrease in

324 the turnover component $\left(\beta_{\mathrm{SIM}-\mathrm{end}}\right)$ was significant in Tambuyukon $\left(\beta_{\mathrm{SIM}-\mathrm{end}}=0.36, p=0.002\right)$, but

325 not in Kinabalu $\left(\beta_{\text {SIM-end }}=0.68, p=0.36\right)$, and that the increase in nestedness $\left(\beta_{\text {NES-end }}\right)$ was

326 significant for Mt. Tambuyukon $\left(\beta_{\mathrm{NES}-\mathrm{end}}=0.38, p=0.001\right)$, but only marginally significant for

327 Mt. Kinabalu $\left(\beta_{\text {NES-end }}=0.14, p=0.05\right)($ Figure 5).

328 The clustering analysis grouped trapping locations in 2 main groups, above and below

$329 \sim 1,400 \mathrm{~m}$ (Figure S3). Within the high elevation group, all locations above $\sim 1,900 \mathrm{~m}$ clustered 330 together. 


\section{Discussion}

332 We report an extensive survey of non-volant small mammals within Kinabalu National Park,

333 Borneo. A sampling effort of 8,231 trap-nights in Mt. Kinabalu $(n=2,044)$ and its neighbor peak

334 Mt. Tambuyukon $(\mathrm{n}=6,187)$ yielded a total of 512 individual records (Mt. Kinabalu, $\mathrm{n}=213$;

335 Mt. Tambuyukon, $\mathrm{n}=299$ ) from 27 species (Mt. Kinabalu, $\mathrm{n}=20 ;$ Mt. Tambuyukon, $\mathrm{n}=23$ )

336 (Table 1; Figure 2). Records from camera traps and direct observations increased the total

337 number of species recorded for Mt. Tambuyukon by 18 to a total of 44 (Table 3).

338 Mt. Kinabalu is a biodiversity hotspot for many taxa (van der Ent 2013). Its mammal

339 fauna has been studied for over a century (eg. Oldfield, 1889; Whitehead, 1893; Emmons, 2000;

340 Nor, 2001) and it is known to host 61 species of non-volant small mammals (Nor, 2001; Payne et

341 al., 2007). We further explored for the first time the non-volant small mammal diversity along

342 the complete elevational gradient in Mt. Tambuyukon $(2,579 \mathrm{~m})$, the third-highest peak in

343 Borneo and only $18 \mathrm{~km}$ away from Mt. Kinabalu. Some important sightings on Mt. Tambuyukon

344 included the orangutan (Pongo pygmaeus), which has an estimated population of only 50

345 individuals within Kinabalu Park boundaries (Ancrenaz et al., 2005). The Kinabalu ferret-badger

346 (Melogale everetti) was a significant finding since it is the first official record of this species on

347 Mt. Tambuyukon (Payne et al., 2007; Wilting et al., 2016). We trapped this species at 2,051 m

348 on Mt. Tambuyukon and 3,336 m on Mt. Kinabalu. We identified a population of the summit rat

349 (Rattus baluensis) on Mt. Tambuyukon, previously only known from Mt. Kinabalu. This species

350 was common at high elevations and has its lower distribution limit at around 2,000 m. A

351 population genetic analysis of the summit rats from Mt. Kinabalu and Mt. Tambuyukon

352 demonstrated that they are currently genetically isolated (Camacho-Sanchez et al. 2018). We 
353 also make the first records of the mountain species Maxomys alticola, Melogale everetti,

354 Hylomys suillus and Niviventer rapit on Mt. Tambuyukon.

355 Alpha diversity

356 Species richness peaked at low elevations on both mountains coinciding with the lowland

357 dipterocarp forest. Then, it decreased gradually towards the highest elevations where it was

358 lowest (Figure 3). This pattern deviates from the expectations of the MDE (Figure 3), and the

359 MDE reported by Nor (2001) in a previous small mammal survey on Mt. Kinabalu with a very

360 similar survey scheme to ours. Colwell \& Lees (2000) suggested that a MDE should constitute

361 the null hypothesis over which deviations should be interpreted. However, this point of view is

362 not universal (Rahbek, 1995; McCain, 2007, 2009). Incomplete sampling of the low elevations

363 happens regularly and can artificially create a MDE (Rahbek, 1995; Lomolino, 2001), which

364 may explain the difference between Nor (2001) and our results for the same mountain. Our

365 surveys detected 12 more species as compared to Nor (2001), including a climbing mouse,

366 Chiropodomys pusillus, a tree rat Lenothrix canus, Prevost's squirrel, Callosciurus prevostii,

367 Jentink's squirrel, Sundasciurus jentinki, the rats Maxomys rajah, M. alticola and Sundamys

368 muelleri, the non-native species Rattus exulans and R. tiomanicus, two species of treeshrews

369 Tupaia longipes and T. minor, and two species of shrews, one trapped in a small Sherman trap,

370 Crocidura sp., and one in a pitfall trap, Suncus sp.. The effects of an incomplete sampling should

371 be more acute in lowland elevations where there is more habitat heterogeneity (Rosenzweig,

372 1992, 1995) and species might tend to occupy smaller ranges (Rosenzweig, 1995; Brown, 2014).

373 However, we report the highest alpha diversity in the lowest elevations, which supports that our

374 sampling scheme was not affected by this low-elevation sampling bias. Another observation

375 supporting the comprehensiveness of our sampling is that we documented species in all sites 
376 between the lowest and highest occurrences, except for M. whiteheadi on Mt. Kinabalu, and $M$.

377 ochraceiventer and N. rapit on Mt. Tambuyukon.

378 Conversely, the gradual decrease of species richness we recorded was explained by

379 elevation alone. Even in the presence of a MDE, a gradual decrease of species richness with

380 elevation seems to be a general pattern in mountain gradients (Rahbek, 1995). There are multiple

381 factors that are correlated with elevation which have been proposed to explain diversity across

382 mountains gradients, but disentangling their effects is difficult given the multicollinearity

383 (Heaney, 2001; Fu et al., 2006; Kluge, Kessler \& Dunn, 2006). The strong correlation of alpha

384 diversity with elevation enables further discussion. Diversity has been proposed to peak with

385 precipitation (Heaney, 2001), but on Mt. Kinabalu the peak of precipitation, at around 2,000 m

386 (Kitayama, 1992), did not match the diversity peak. Productivity (Aiba, Takyu \& Kitayama,

387 2005) and temperature (Kitayama, 1992) are negatively correlated with elevation in Kinabalu,

388 and could potentially explain the diversity pattern. Nevertheless, it has been suggested that

389 examining resource availability for this taxonomic group is more appropriate than simply

390 looking at productivity (Brown, 2001; Heaney, 2001). However, this is a difficult variable to

391 measure that was not incorporated in our original survey experimental design. A more plausible

392 explanation for the change in diversity is area and habitat complexity. Available area (Camacho-

393 Sanchez et al., 2018) and complexity of the forest (Kitayama, 1992) decrease with elevation on

394 Mt. Kinabalu. The peak in diversity we find in low elevations is consistent with the spatial

395 hypothesis which states that (1) at the regional level, larger areas (such as the lower elevations in

396 mountains) have lower rates of extinction over speciation (Rosenzweig, 1992) and (2) that larger

397 areas have more types of different habitats, so greater species diversity should be observed in

398 larger areas (Rosenzweig, 1995). Perhaps, the relationship between area and diversity on 
399 elevational gradients along large mountains falls somewhere between these processes (McCain,

400 2007).

401 Beta diversity

402 The composition of the small mammal assemblage changed across elevation in a similar

403 way between mountains. Indeed, all trapping locations in high elevations (above $\sim 1,900 \mathrm{~m}$ ) were

404 very similar in composition (Figure S3). Mid-mountain locations showed intermediate

405 compositions whereas the $500 \mathrm{~m}$ and $900 \mathrm{~m}$ locations on both mountains also clustered together.

406 This montane fauna transition was already identified by Nor (2001) to be at around 1,800 m, and

407 it matches approximately the vegetation limit between the lower and upper montane forests on

408 Mt. Kinabalu (Kitayama 1992). The influence of this shift is reflected in the overall high

409 turnover component of beta diversity $\left(\beta_{\mathrm{SIM}}\right)$ for both mountains (Figure 5). The pairwise turnover

410 components $\left(\beta_{\text {sim }}\right)$ were highest between lowland - highland locations (Tables S3). This indicates

411 the lowland and highland communities are composed of different species, rather than the

412 community with the lowest richness (highland) being a subset of the species present on the

413 richest one (lowland). This pattern has already been described for other small mammals across

414 several mountain systems (Mena \& Vázquez-Domínguez, 2005). Unfortunately, there is no

415 consistent data collection from other tall mountains in Sundaland to discuss a common mountain

416 biogeography pattern in this region. Historical expeditions to Sumatra also point to a similar shift

417 in vegetation structure and different mammal assemblages at high elevations above 2,000 $\mathrm{m}$

418 (Robinson \& Kloss, 1918, 1919; Miller, 1942).

419 Pattern of endemism

420 Beyond the net alpha and beta diversity we describe, we place special attention on the

421 nature of the species that could be driving these diversity patterns. Our models predicted that the 
422 proportion of Bornean endemism as well as the proportion of endemic species captured increased

423 with elevation (Figure 4). At the same time, we found that the high-elevation endemics were

424 responsible for the high turnover component in beta diversity in both mountains (Figure 5). The

425 species that had the greatest contribution to this high-elevation endemism were Rattus baluensis,

426 Tupaia montana, Sundasciurus everetti and Maxomys alticola (Table S1). These species are

427 restricted to mountain areas in northern or central-northern Borneo, and were present in high

428 abundance and evenness from 2,000 m (Table S1). Nor (2001) reported high trapping success on

429 Mt. Kinabalu, associated with higher abundance at these elevations, but he did not record

430 Maxomys alticola. Heaney (2001) also recorded the highest abundances in the top elevations in

431 the Philippines, and a peak of endemics at higher elevations. Three additional trapped species are

432 mountain endemics (Melogale everetti, Sundasciurus jentinki and Niviventer rapit) but

433 contributed less to our analysis because of their lower densities or detectability. This pattern of

434 high-elevation endemics could be even more pronounced as the distribution and taxonomy of the

435 highland mammals also found on other islands in Sundaland are further updated and revised (i.e.

Hylomys suillus and Sundamys infraluteus; Camacho Sánchez, 2017). A majority of the lowland

437 species are widespread, and also distributed across other Sundaland landmasses such as Sumatra 438 and the Malay Peninsula (Corbet \& Hill, 1992).

439 The pattern of mountain endemics on Mt. Kinabalu has previously been described for 440 other taxa (Merckx et al., 2015). For mammals, this has also been observed by Heaney (2001),

441 Sanchez-Cordero (2001), Swenson et al. (2012) and Chen et al. (2017) on other mountains. Mt

442 Kinabalu is unique in Sunland due to its high elevation $(4,095 \mathrm{~m})$ and the scarcity of nearby

443 peaks above $2,000 \mathrm{~m}$. Higher isolation on mountain peaks boosts mountain endemism worldwide

444 (Steinbauer et al., 2016), which could explain the greater endemism in the higher elevations in 
445 the Kinabalu range. For instance, a pattern of mountain endemism linked to divergence in

446 allopatry induced by isolation from the combination of topography with past climate changes has

447 been described in Bornean birds (Sheldon, Lim \& Moyle, 2015; Moyle et al., 2017; Manthey et

448 al., 2017). A similar pattern of high mountain endemism driven by intra-island speciation has

449 been reported for shrews in Sumatra and Java (Esselstyn et al., 2013; Demos et al., 2016).

450 Presumably, the high degree of isolation of the habitats on the higher slopes of Mt. Kinabalu help

451 to maintain a highly endemic community. This could be due to reduced dispersal and

452 colonization to/from nearby similar areas as proposed by Steinbauer et al. (2016).

\section{Conclusions}

454 We found a decline in small mammal diversity from low to high elevations on both Mt. Kinabalu

455 and Mt. Tambuyukon. This pattern differs from the MDE previously described for Mt. Kinabalu

456 and other mountains worldwide. The decrease in diversity with elevation is concordant with the

457 spatial hypothesis predicting higher diversity in lowlands driven by historically larger areas with

458 less extinction and more habitat heterogeneity. However, we cannot exclude other climatic or

459 ecological hypothesis. Endemic species were in higher proportion and more abundant in higher

460 elevations and they drove the turnover component of beta diversity. The high number of

461 mountain endemics point to historical factors as important drivers of the biogeography in this

462 region.

\section{Acknowledgements}

464 This research would not have been possible without the help and assistance from many

465 individuals. This includes logistical support from Maklarin Lakim, Alim Buin, Paul Imbun,

466 Justin Sator, Robert Stuebing, Fred Sheldon and Konstans Wells. Kristofer Helgen assisted in

467 many aspects of this work. Darrin Lunde is thanked for assistance with preparation prior to the 
468 field expeditions, and for the use of traps from the Division of Mammals at the National Museum

469 of Natural History. Larry Rockwood allowed use of several of the camera traps, and for that we

470 are grateful. Megan Whatton assisted with the calculations for the camera trap data. Jeffrey

471 Hanson advised on how to correct for autocorrelation. Field Crew: Rose Ragai, Lyndon

472 Hawkins, Flavia Porto, Manolo Lopez, Paco Carro, Ipe, and Anzlys. Logistical support was

473 provided by the infrastructures offered by Doñana's Singular Scientific-Technical Infrastructure

474 (ICTS-EBD).

475

476

477

478

479

480

481

482

483

484

485

486

487

488

489

490

491

492

493

494

495

496

497

498

499

500

501

502

503

504

505

Aiba SI, Kitayama K. 1999. Structure, composition and species diversity in an altitude-substrate matrix of rain forest tree communities on Mount Kinabalu, Borneo. Plant Ecology 140:139157. DOI: $10.1023 / \mathrm{A}: 1009710618040$.

Aiba SI, Takyu M, Kitayama K. 2005. Dynamics, productivity and species richness of tropical rainforests along elevational and edaphic gradients on Mount Kinabalu, Borneo. Ecological Research 20:279-286. DOI: 10.1007/s11284-005-0043-z.

Ancrenaz M, Gimenez O, Ambu L, Ancrenaz K, Andau P, Goossens B, Payne J, Sawang A, Tuuga A, Lackman-Ancrenaz I. 2005. Aerial surveys give new estimates for orangutans in Sabah, Malaysia. PLoS biology 3:e3. DOI: 10.1371/journal.pbio.0030003.

Baselga A. 2010. Partitioning the turnover and nestedness components of beta diversity. Global Ecology and Biogeography 19:134-143. DOI: 10.1111/j.1466-8238.2009.00490.x.

Baselga A, Orme CDL. 2012. Betapart: An R package for the study of beta diversity. Methods in Ecology and Evolution 3:808-812. DOI: 10.1111/j.2041-210X.2012.00224.x.

Bates D, Mächler M, Bolker B, Walker S. 2015. Fitting Linear Mixed-Effects Models Using lme4. Journal of Statistical Software 67:1-48. DOI: 10.18637/jss.v067.i01.

Beaman JH, Anderson C. 1997. The summit flora of Mt. Murud, Sarawak, Malaysia. Contributions from the University of Michigan Herbarium 21:85-141.

Beck J, Chey VK. 2008. Explaining the elevational diversity pattern of geometrid moths from Borneo: a test of five hypotheses. Journal of Biogeography 35:1452-1464. DOI: 10.1111/j.1365-2699.2008.01886.x.

Brown JH. 2001. Mammals on mountainsides: elevational patterns of diversity. Global Ecology and Biogeography 10:101-109.

Brown JH. 2014. Why are there so many species in the tropics? Journal of Biogeography 41:822. DOI: $10.1111 /$ jbi.12228.

Brühl CA, Mohamed M, Linsenmair KE. 1999. Altitudinal distribution of leaf litter ants along a transect in primary forests on Mount Kinabalu, Sabah, Malaysia. Journal of Tropical Ecology. DOI: 10.1017/s0266467499000802.

Camacho-Sanchez M, Quintanilla I, Hawkins MTR, Tuh FYY, Wells K, Maldonado JE, Leonard JA. 2018. Interglacial refugia on tropical mountains: Novel insights from the summit rat (Rattus baluensis), a Borneo mountain endemic. Diversity and Distributions 24:1252-1266. 
506

507

508

509

510

511

512

513

514

515

516

517

518

519

520

521

522

523

524

525

526

527

528

529

530

531

532

533

534

535

536

537

538

539

540

541

542

543

544

545

546

547

548

549

550

551

DOI: 10.1111/ddi.12761.

Camacho Sánchez M. 2017. Evolution in Sundaland: insights from comparative phylogeography of Rattus and Sundamys rats. University Pablo de Olavide.

Chen Z, He K, Cheng F, Khanal L, Jiang X. 2017. Patterns and underlying mechanisms of nonvolant small mammal richness along two contrasting mountain slopes in southwestern China. Scientific Reports 7:1-10. DOI: 10.1038/s41598-017-13637-0.

Collins NM. 1980. The distribution of soil macrofauna on the west ridge of Gunung (Mount) Mulu, Sarawak. Oecologia 44:263-275. DOI: 10.1007/BF00572689.

Colwell RK, Lees DC. 2000. The mid-domain effect: Geometric constraints on the geography of species richness. Trends in Ecology and Evolution 15:70-76. DOI: 10.1016/S01695347(99)01767-X.

Corbet GB, Hill JE. 1992. The mammals of the Indomalayan region: a systematic review. Oxford University Press.

Demos TC, Achmadi AS, Giarla TC, Handika H, Maharadatunkamsi, Rowe KC, Esselstyn JA. 2016. Local endemism and within-island diversification of shrews illustrate the importance of speciation in building Sundaland mammal diversity. Molecular Ecology 25:5158-5173. DOI: $10.1111 / \mathrm{mec} .13820$.

Dixon P. 2003. VEGAN, a package of R functions for community ecology. Journal of Vegetation Science 14:927-930. DOI: 10.1111/j.1654-1103.2003.tb02228.x.

Emmons LH. 2000. Tupai: A Field Study of Bornean Treeshrews. University of California Press. van der Ent A. 2013. Kinabalu. Kota Kinabalu, Sabah: Natural History Publications.

Esselstyn J a, Maharadatunkamsi, Achmadi AS, Siler CD, Evans BJ. 2013. Carving out turf in a biodiversity hotspot: multiple, previously unrecognized shrew species co-occur on Java Island, Indonesia. Molecular Ecology 22:4972-4987. DOI: 10.1111/mec.12450.

Fu C, Hua X, Li J, Chang Z, Pu Z, Chen J, Pu Z, Hua X, Chang Z, Li J, Fu C. 2006. Elevational patterns of frog species richness and endemic richness in the Hengduan Mountains, China: geometric constraints, area and climate effects. Ecography 29:919-927. DOI: 10.1111/j.2006.0906-7590.04802.x.

Grytnes JA, Beaman JH. 2006. Elevational species richness patterns for vascular plants on Mount Kinabalu, Borneo. Journal of Biogeography 33:1838-1849. DOI: 10.1111/j.13652699.2006.01554.x.

Grytnes J-A, Beaman JH, Romdal TS, Rahbek C. 2008. The mid-domain effect matters: simulation analyses of range-size distribution data from Mount Kinabalu, Borneo. Journal of Biogeography 35:2138-2147. DOI: 10.1111/j.1365-2699.2008.01952.x.

Harrison XA, Donaldson L, Correa-Cano ME, Evans J, Fisher DN, Goodwin CED, Robinson BS, Hodgson DJ, Inger R. 2018. A brief introduction to mixed effects modelling and multimodel inference in ecology. PeerJ 2018:1-32. DOI: 10.7717/peerj.4794.

Hasegawa M, Ito MT, Kitayama K. 2006. Community structure of oribatid mites in relation to elevation and geology on the slope of Mount Kinabalu, Sabah, Malaysia. European Journal of Soil Biology 42:S191-S196. DOI: 10.1016/j.ejsobi.2006.07.006.

Hawkins MTR, Helgen KM, Maldonado JE, Rockwood LL, Tsuchiya MTN, Leonard JA. 2016. Phylogeny, biogeography and systematic revision of plain long-nosed squirrels (genus Dremomys, Nannosciurinae). Molecular Phylogenetics and Evolution 94:752-764. DOI: 10.1016/j.ympev.2015.10.023.

Heaney LR. 1986. Biogeography of mammals in SE Asia: estimates of rates of colonization, extinction and speciation. Biological Journal of the Linnean Society 28:127-165.

Peer] reviewing PDF | (2017:12:22659:3:1:NEW 4 Sep 2019) 
552

553

554

555

556

557

558

559

560

561

562

563

564

565

566

567

568

569

570

571

572

573

574

575

576

577

578

579

580

581

582

583

584

585

586

587

588

589

590

591

592

593

594

595

596

597

Heaney LR. 2001. Small Mammal Diversity along Elevational Gradients in the Philippines: An Assessment of Patterns and Hypotheses. Global Ecology and Biogeography 10:15-39.

Hu Y, Jin K, Huang Z, Ding Z, Liang J, Pan X, Hu H, Jiang Z. 2017. Elevational patterns of nonvolant small mammal species richness in Gyirong Valley, Central Himalaya: Evaluating multiple spatial and environmental drivers. Journal of Biogeography. DOI: 10.1111/jbi.13102.

King G. 2010. Unifying political methodology: The likelihood theory of statistical inference. University of Michigan Press.

Kitayama K. 1992. An altitudinal Borneo transect study of the vegetation on Mount kinabalu, Borneo. Plant Ecology 102:149-171. DOI: 10.1007/BF00044731.

Kitayama K, Kulip J, Nais J, Biun A. 1993. Vegetation Survey on Mount Trus Madi, Borneo a Prospective New Mountain Park. Mountain Research and Development 13:99-105. DOI: $10.2307 / 3673647$.

Kluge J, Kessler M, Dunn RR. 2006. What drives elevational patterns of diversity? A test of geometric constraints, climate and species pool effects for pteridophytes on an elevational gradient in Costa Rica. Global Ecology and Biogeography 15:358-371. DOI: 10.1111/j.1466-822X.2006.00223.x.

Laird NM, Ware JH. 1982. Random-effects models for longitudinal data. Biometrics 38:963974.

Laumonier Y. 1997. The Vegetation and Physiography of Sumatra. Dordrecht: Springer Netherlands. DOI: 10.1007/978-94-009-0031-8.

Li JS, Song YL, Zeng ZG. 2003. Elevational gradients of small mammal diversity on the northern slopes of Mt. Qilian, China. Global Ecology and Biogeography 12:449-460. DOI: 10.1046/j.1466-822X.2003.00052.x.

Liew TS, Schilthuizen M, bin Lakim M. 2010. The determinants of land snail diversity along a tropical elevational gradient: Insularity, geometry and niches. Journal of Biogeography 37:1071-1078. DOI: 10.1111/j.1365-2699.2009.02243.x.

Lomolino M V. 2001. Elevation gradients of species-density: Historical and prospective views. Global Ecology and Biogeography. DOI: 10.1046/j.1466-822x.2001.00229.x.

Lomolino M V., Riddle BR, Whittaker RJ, Brown JH. 2010. Biogeography. Sunderland, MA: Sinauer Associates, Inc.

Malsch AKF, Fiala B, Maschwitz U, Mohamed M, Nais J, Linsenmair KE. 2008. An analysis of declining ant species richness with increasing elevation at Mount Kinabalu, Sabah, Borneo. Asian Myrmecology 2:33-49. DOI: 10.20362/am.002004.

Manthey JD, Moyle RG, Gawin DF, Rahman MA, Ramji MFS, Sheldon FH. 2017. Genomic phylogeography of the endemic Mountain Black-eye of Borneo (Chlorocharis emiliae): montane and lowland populations differ in patterns of Pleistocene diversification. Journal of Biogeography 44:2272-2283. DOI: 10.1111/jbi.13028.

Marathe A. 2019. rangemodelR: Mid-Domain Effect and Species Richness. R package version 1.0.4.

McCain CM. 2004. The mid-domain effect applied to elevational gradients: species richness of small mammals in Costa Rica. Journal of Biogeography 31:19-31. DOI: 10.1046/j.03050270.2003.00992.x.

McCain CMM. 2005. Elevational Gradients in Diversity of Small Mammals. Ecology 86:366372.

McCain CM. 2007. Could temperature and water availability drive elevational species richness

Peer] reviewing PDF | (2017:12:22659:3:1:NEW 4 Sep 2019) 
598

599

600

601

602

603

604

605

606

607

608

609

610

611

612

613

614

615

616

617

618

619

620

621

622

623

624

625

626

627

628

629

630

631

632

633

634

635

636

637

638

639

640

641

642

643

patterns? A global case study for bats. Global Ecology and Biogeography 16:1-13. DOI: 10.1111/j.1466-8238.2006.00263.x.

McCain CM. 2009. Global analysis of bird elevational diversity. Global Ecology and Biogeography 18:346-360. DOI: 10.1111/j.1466-8238.2008.00443.x.

Mena JL, Vázquez-Domínguez E. 2005. Species turnover on elevational gradients in small rodents. 14:539-547. DOI: 10.1111/j.1466-822x.2005.00189.x.

Merckx VSFTSFT, Hendriks KPP, Beentjes KKK, Mennes CBB, Becking LEE, Peijnenburg KTCATC a., Afendy A, Arumugam N, de Boer H, Biun A, Buang MM, Chen P-P, Chung AYC, Dow R, Feijen F a. a., Feijen H, Soest CF, Geml J, Geurts R, Gravendeel B, Hovenkamp P, Imbun P, Ipor I, Janssens SB, Jocqué M, Kappes H, Khoo E, Koomen P, Lens F, Majapun RJ, Morgado LN, Neupane S, Nieser N, Pereira JT, Rahman H, Sabran S, Sawang A, Schwallier RM, Shim P-S, Smit H, Sol N, Spait M, Stech M, Stokvis F, Sugau JB, Suleiman M, Sumail S, Thomas DC, van Tol J, Tuh FYY, Yahya BE, Nais J, Repin R, Lakim M, Schilthuizen M. 2015. Evolution of endemism on a young tropical mountain. Nature 524:347-350. DOI: 10.1038/nature14949.

Miller GS. 1942. Zoological Results of the George Vanderbilt Sumatran Expedition, 1936-1939. Part V: Mammals Collected by Frederick A. Ulmer, Jr. on Sumatra and Nias. Proceedings of the National Academy of Sciences of Philadelphia 94:107-165.

Moyle RG, Manthey JD, Hosner PA, Rahman M, Lakim M, Sheldon FH. 2017. A genome-wide assessment of stages of elevational parapatry in Bornean passerine birds reveals no introgression: implications for processes and patterns of speciation. PeerJ 5:e3335. DOI: 10.7717/peerj.3335.

Myers N, Mittermeier RA, Mittermeier CG, da Fonseca GAB, Kent J. 2000. Biodiversity hotspots for conservation priorities. Nature 403:853-8. DOI: 10.1038/35002501.

Nickerson RS. 2000. Null hypothesis significance testing: A review of an old and continuing controversy. Psychological Methods 5:241-301. DOI: 10.1037/1082-989X.5.2.241.

Nor SM. 2001. Elevational diversity patterns of small mammals on Mount Kinabalu, Sabah, Malaysia. Global Ecology and Biogeography 10:41-62. DOI: 10.1046/j.1466822x.2001.00231.x.

Oldfield T. 1889. On the Mammals of Mount Kina Balu, North Borneo. Proceedings of the Zoological Society of London.

Patterson BD, Stotz DF, Solari S. 1998. Contrasting patterns of elevational zonation for birds and mammals in the Andes of southeastern Peru. Journal of Biogeography 25:593-607.

Payne J, Francis CM, Phillipps K. 1985. A Field Guide to the Mammals of Borneo. Kota Kinabalu, Sabah: The Sabah Society.

Payne J, Francis CM, Phillipps K, Phillips K. 2007. A Field Guide to the Mammals of Borneo. Kota Kinabalu, Sabah: The Sabah Society.

Pinheiro J, Bates D. 2006. Mixed-effects models in S and S-PLUS. Springer Science \& Business Media.

Pinheiro J, Bates D, DebRoy S, Sarkar D, R Core Team. 2018. nlme: Linear and Nonlinear Mixed Effects Models.

R Development Core Team. 2018. R: A language and environment for statistical computing. Vienna, Austria.

Rahbek C. 1995. The elevational gradient of species richness: a uniform pattern? Ecography 2:200-205. DOI: 10.1111/j.1600-0587.1995.tb00341.x.

Rickart EA. 2001. Elevational diversity gradients, biogeography and the structure of montane

Peer) reviewing PDF | (2017:12:22659:3:1:NEW 4 Sep 2019) 
644

645

646

647

648

649

650

651

652

653

654

655

656

657

658

659

660

661

662

663

664

665

666

667

668

669

670

671

672

673

674

675

676

677

678

679

680

681

682

683

684

685

686

687

688

689

mammal communities in the intermountain region of north America. Global Ecology and Biogeography 10:77-100. DOI: 10.1046/j.1466-822x.2001.00223.x.

Robinson H, Kloss C. 1918. Results of an expedition to Korinchi Peak, 12,400 ft., Sumatra. 1. Mammals. Journal of the Federated Malay State Museums 8:1-80.

Robinson H, Kloss C. 1919. On Mammals chiefly from the Ophir district, West Sumatra. Journal of the Federated Malay State Museums 7:299-323.

Rosenzweig ML. 1992. Species Diversity Gradients: We Know More and Less Than We Thought. Journal of Mammalogy 73:715-730. DOI: 10.2307/1382191.

Rosenzweig M. 1995. Species diversity in space and time. Cambridge University Press.

Rowe RJ. 2009. Environmental and geometric drivers of small mammal diversity along elevational gradients in Utah. Ecography 32:411-422. DOI: 10.1111/j.16000587.2008.05538.x.

Rowe RJ, Heaney LR, Rickart E a. 2015. Scale effects on the pattern and predictors of small mammal diversity along a local elevational gradient in the Great Basin. Journal of Biogeography:n/a-n/a. DOI: 10.1111/jbi.12554.

Saitou N, Nei M. 1987. The neighbor-joining method: a new method for reconstructing phylogenetic trees. Molecular Biology and Evolution 4:406-425. DOI: 10.1093/oxfordjournals.molbev.a040454.

Sánchez-Cordero V. 2001. Elevation gradients of diversity for rodents and bats in Oxaca, Mexico. Global Ecology and Biogeography 10:63-76.

Sheldon FH, Lim HC, Moyle RG. 2015. Return to the Malay Archipelago: the biogeography of Sundaic rainforest birds. Journal of Ornithology 156:91-113. DOI: 10.1007/s10336-0151188-3.

Sikes RS, Gannon WL, Care A, of the American Society of Mammalogists UC. 2011. Guidelines of the American Society of Mammalogists for the Use of Wild Mammals in Research. Journal of Mammalogy 91:235-253.

Steinbauer MJ, Field R, Grytnes JA, Trigas P, Ah-Peng C, Attorre F, Birks HJB, Borges PAV, Cardoso P, Chou CH, De Sanctis M, de Sequeira MM, Duarte MC, Elias RB, FernándezPalacios JM, Gabriel R, Gereau RE, Gillespie RG, Greimler J, Harter DEV, Huang TJ, Irl SDH, Jeanmonod D, Jentsch A, Jump AS, Kueffer C, Nogué S, Otto R, Price J, Romeiras MM, Strasberg D, Stuessy T, Svenning JC, Vetaas OR, Beierkuhnlein C. 2016. Topography-driven isolation, speciation and a global increase of endemism with elevation. Global Ecology and Biogeography 25:1097-1107. DOI: 10.1111/geb.12469.

Stevens RD, Rowe RJ, Badgley C. 2019. Gradients of mammalian biodiversity through space and time. Journal of Mammalogy 100:1069-1086. DOI: 10.1093/jmammal/gyz024.

Swenson JJ, Young BE, Beck S, Comer P, Córdova JH, Dyson J, Embert D, Encarnación F, Ferreira W, Franke I, Grossman D, Hernandez P, Herzog SK, Josse C, Navarro G, Pacheco V, Stein BA, Timaná M, Tovar A, Tovar C, Vargas J, Zambrana-Torrelio CM. 2012. Plant and animal endemism in the eastern Andean slope: challenges to conservation. $B M C$ Ecology 12:1. DOI: 10.1186/1472-6785-12-1.

Wallace AR. 1869. The Malay Archipelago: The land of the orang-utan, and the bird of paradise. A narrative of travel, with studies of man and nature. London: Macmillan.

Wang X, Fang J. 2012. Constraining null models with environmental gradients: A new method for evaluating the effects of environmental factors and geometric constraints on geographic diversity patterns. Ecography 35:1147-1159. DOI: 10.1111/j.1600-0587.2012.07384.x.

Wells, Pf, Lakim, Linsenmair KE, Wells K, Pfeiffer M, Lakim MB, Linsenmair KE. 2004. Use

Peer] reviewing PDF | (2017:12:22659:3:1:NEW 4 Sep 2019) 
690 of arboreal and terrestrial space by a small mammal community in a tropical rainforest in

691 Borneo, Malaysia. Journal of Biogeography 31:641-652.

692 Whitehead J. 1893. Exploration of Mount Kina Balu, North Borneo. London.

693 Wilting A, Hearn AJ, Eaton J, Belant JL, Kramer-Schadt S. 2016. Predicted distribution of the 694 Bornean ferret badger Melogale everetti (Mammalia: Carnivora: Mustelidae) on Borneo. 695 Raffles Bulletin of Zoology 2016:55-60.

696 Wood JJ, van der Ent A. 2012. Mount Tambuyukon-An Intriguing Mountain and its Orchids.

697

698

699 Supplementary Information

700 Dataset S1: Data on animals sampled and trapping effort.

701 Table S1: Summary table of species per elevation.

702 Figure S1: Trap-night accumulation curves

703 Figure S2: Photographs from camera traps.

704 Table S2: Diversity indices.

705 Figure S3: Cluster analysis.

706 Tables S3: Pairwise beta diversity. 


\section{Table 1 (on next page)}

Trap success across all elevations.

Trap success across all elevations. The number of animals caught is in column $\mathrm{N}$, followed by number of trap nights, and the overall trap success per altitude. 
Table 1: Trap success across all elevations. The number of animals caught is in column $\mathrm{N}$,

followed by number of trap nights, and the overall trap success per altitude.

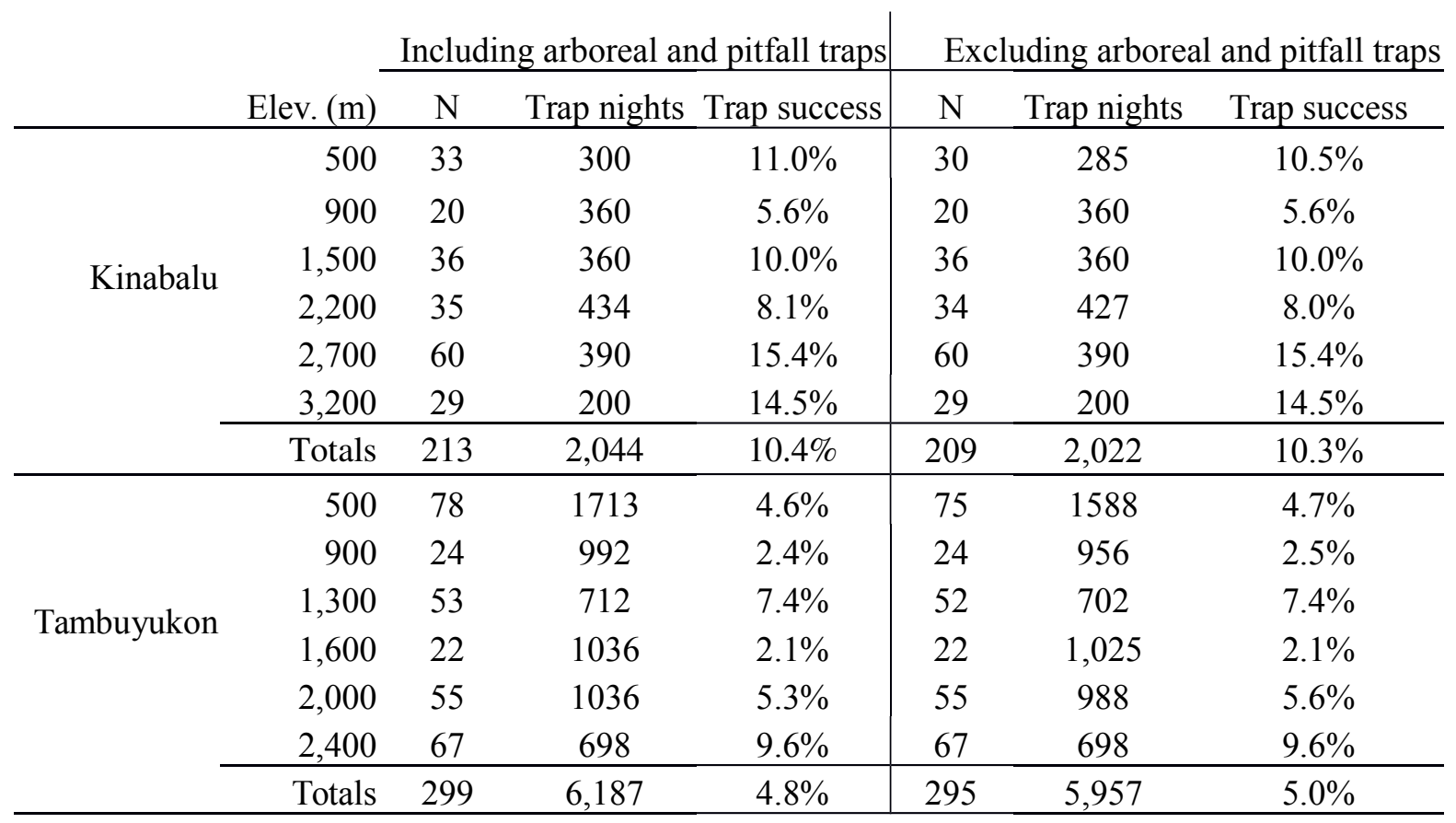




\section{Table 2 (on next page)}

Results of camera trap survey.

Results of camera trap surveys on Mt. Tambuyukon, with relative abundance calculated for 100 trap nights. 
1 Table 2: Results of camera trap surveys on Mt. Tambuyukon, with relative abundance calculated 2 for 100 trap nights.

\begin{tabular}{|c|c|c|c|c|c|c|}
\hline Camera & $\begin{array}{c}\text { Elevation } \\
(\mathrm{m})\end{array}$ & Common Name & Species & $\begin{array}{l}\text { No. of } \\
\text { series }\end{array}$ & $\begin{array}{c}\text { Camera } \\
\text { nights }\end{array}$ & $\begin{array}{c}\text { Relative } \\
\text { abundance }\end{array}$ \\
\hline \multirow{5}{*}{1} & \multirow{5}{*}{500} & $\begin{array}{c}\text { Pig-tailed } \\
\text { Macaque }\end{array}$ & Macaca nemestrina & 1 & 42 & 2.38 \\
\hline & & $\begin{array}{l}\text { Common } \\
\text { Porcupine }\end{array}$ & Hystrix brachyura & 2 & & 4.76 \\
\hline & & Mouse Deer & Tragulus sp. & 2 & & 4.76 \\
\hline & & Muntjac & Muntiacus sp. & 1 & & 2.38 \\
\hline & & Sambar Deer & Rusa unicolor & 1 & & 2.38 \\
\hline \multirow{2}{*}{2} & \multirow{2}{*}{900} & Malay Civet & Viverra tangalunga & 2 & 42 & 9.52 \\
\hline & & Banded Linsang & Prionodon linsang & 1 & & 2.38 \\
\hline 3 & 900 & Malay Civet & Viverra tangalunga & 2 & & ---- \\
\hline \multirow[b]{2}{*}{4} & \multirow[b]{2}{*}{1,300} & Malay Civet & Viverra tangalunga & 1 & 29 & 3.45 \\
\hline & & $\begin{array}{r}\text { Masked Palm } \\
\text { Civet }\end{array}$ & Paguma larvata & 1 & & 3.45 \\
\hline
\end{tabular}

3

4 


\section{Table 3(on next page)}

All species recorded on Mt. Tambuyukon.

All species recorded on Mt. Tambuyukon. 
1 Table 3: All species recorded on Mt. Tambuyukon.

\begin{tabular}{|c|c|c|c|c|}
\hline Number & Family & Common name & Scientific name & $\begin{array}{l}\text { Method(s) of } \\
\text { detection }\end{array}$ \\
\hline 1 & Cercopithecidae & Pig-tailed Macaque & Macaca nemestrina & $\begin{array}{l}\text { camera trap/ } \\
\text { observation }\end{array}$ \\
\hline 2 & Cercopithecidae & Long tailed Macaque & Macaca fascicularis & observation \\
\hline 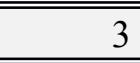 & Cercopithecidae & Maroon Langur & Presbytis rubicunda & observation \\
\hline 4 & Cervidae & Muntjac & Muntiacus sp. & camera trap \\
\hline 5 & Cervidae & Sambar Deer & Cervus unicolor & $\begin{array}{l}\text { camera trap/ } \\
\text { observation }\end{array}$ \\
\hline 6 & Erinaceidae & Lesser Gymnure & Hylomys suillus & live trap \\
\hline 7 & Hylobatidae & Bornean Gibbon & Hylobates muelleri & observation \\
\hline 8 & "Hystricidae & "Common Porcupine & Hystrix brachyura & camera trap \\
\hline 9 & Muridae & $\begin{array}{l}\text { Common Pencil-tailed Tree } \\
\text { Mouse }\end{array}$ & $\begin{array}{l}\text { Chiropodomys } \\
\text { pusillus }\end{array}$ & live trap \\
\hline 10 & Muridae & $\begin{array}{l}\text { Grey tree rat/ Sundaic } \\
\text { Lenothrix }\end{array}$ & Lenothrix canus & live trap \\
\hline 11 & Muridae & Long-tailed giant rat & Leopoldomys sabanus & live trap \\
\hline 12 & Muridae & "Bornean Mountain Maxomys & Maxomys alticola & live trap \\
\hline 13 & Muridae & Chestnut-bellied spiny rat & $\begin{array}{l}\text { Maxomys } \\
\text { ochraceiventer }\end{array}$ & live trap \\
\hline 14 & Muridae & Brown Spiny Rat & Maxomys rajah & live trap \\
\hline 15 & Muridae & Red Spiny Rat & Maxomys surifer & live trap \\
\hline 16 & Muridae & Whitehead's Rat & Maxomys whiteheadi & live trap \\
\hline 18 & Muridae & Dark-tailed tree rat & $\begin{array}{l}\text { Niviventer } \\
\text { cremrioventer }\end{array}$ & live trap \\
\hline 19 & Muridae & Mountain long tailed rat & Niviventer rapit & live trap \\
\hline 20 & Muridae & Summit Rat & Rattus baluensis & live trap \\
\hline 21 & Muridae & Polynesian/Pacific rat & Rattus exulans & live trap \\
\hline 22 & Muridae & Giant Mountain Rat & Sundamys infraluteus & live trap \\
\hline 23 & Muridae & Muller's Rat/ Sundamys & Sundamys muelleri & live trap \\
\hline 24 & Mustelidae & Kinabalu ferret-badger & Melogale everetti & live trap \\
\hline 25 & Pongidae & Bornean Orangutan & Pongo pygmaeus & observation \\
\hline 26 & Sciuridae & $\begin{array}{l}\text { Bornean Mountain Ground } \\
\text { Squirrel }\end{array}$ & Sundasciurus everetti & live trap \\
\hline 27 & Sciuridae & Low's squirrel & Sundasciurus lowii & live trap \\
\hline 28 & Sciuridae & Plantain Squirrel & Callosciurus notatus & observation \\
\hline 29 & Sciuridae & Kinabalu Squirrel & $\begin{array}{l}\text { Callosciurus } \\
\text { baluensis }\end{array}$ & observation \\
\hline 30 & Sciuridae & Giant Squirrel & Ratufa affinis & observation \\
\hline 31 & Sciuridae & Jentink's Squirrel & Sundasciurus jentinki & live trap \\
\hline
\end{tabular}




\begin{tabular}{|clll|l|}
\hline \hline 32 & Sciuridae & Whitehead's Squirrel & $\begin{array}{l}\text { Exilisciurus } \\
\text { whiteheadi }\end{array}$ & observation \\
\hline \hline 33 & Sciuridae & $\begin{array}{l}\text { Giant Bornean Tufted } \\
\text { Ground Squirrel }\end{array}$ & $\begin{array}{l}\text { Reithrosciurus } \\
\text { macrotis }\end{array}$ & observation \\
\hline \hline 34 & Soricidae & Shrew & Crocidura sp. & live trap \\
\hline \hline 35 & Soricidae & Shrew & Suncus sp. & live trap \\
\hline \hline 36 & Suidae & Bearded Pig & Sus barbatus & observation \\
\hline \hline 37 & Tragulidae & Mouse Deer & Tragulus sp. & camera trap \\
\hline \hline 38 & Tupaiidae & Common treeshrew & Tupaia longipes & live trap \\
\hline \hline 39 & Tupaiidae & Lesser treeshrew & Tupaia minor & live trap \\
\hline \hline 40 & Tupaiidae & Mountain treeshrew & Tupaia montana & live trap \\
\hline \hline 41 & Tupaiidae & Large treeshrew & Tupaia tana & live trap \\
\hline \hline 42 & Viverridae & Malay Civet & Viverra tangalunga & camera trap \\
\hline \hline 43 & Viverridae & Banded Linsang & Prionodon linsang & camera trap \\
\hline \hline 44 & Viverridae & Masked Palm Civet & Paguma larvata & camera trap \\
\hline
\end{tabular}


Figure 1

Trapping locations

Map of Kinabalu Park, Sabah, Malaysia with trails followed and trapping locations

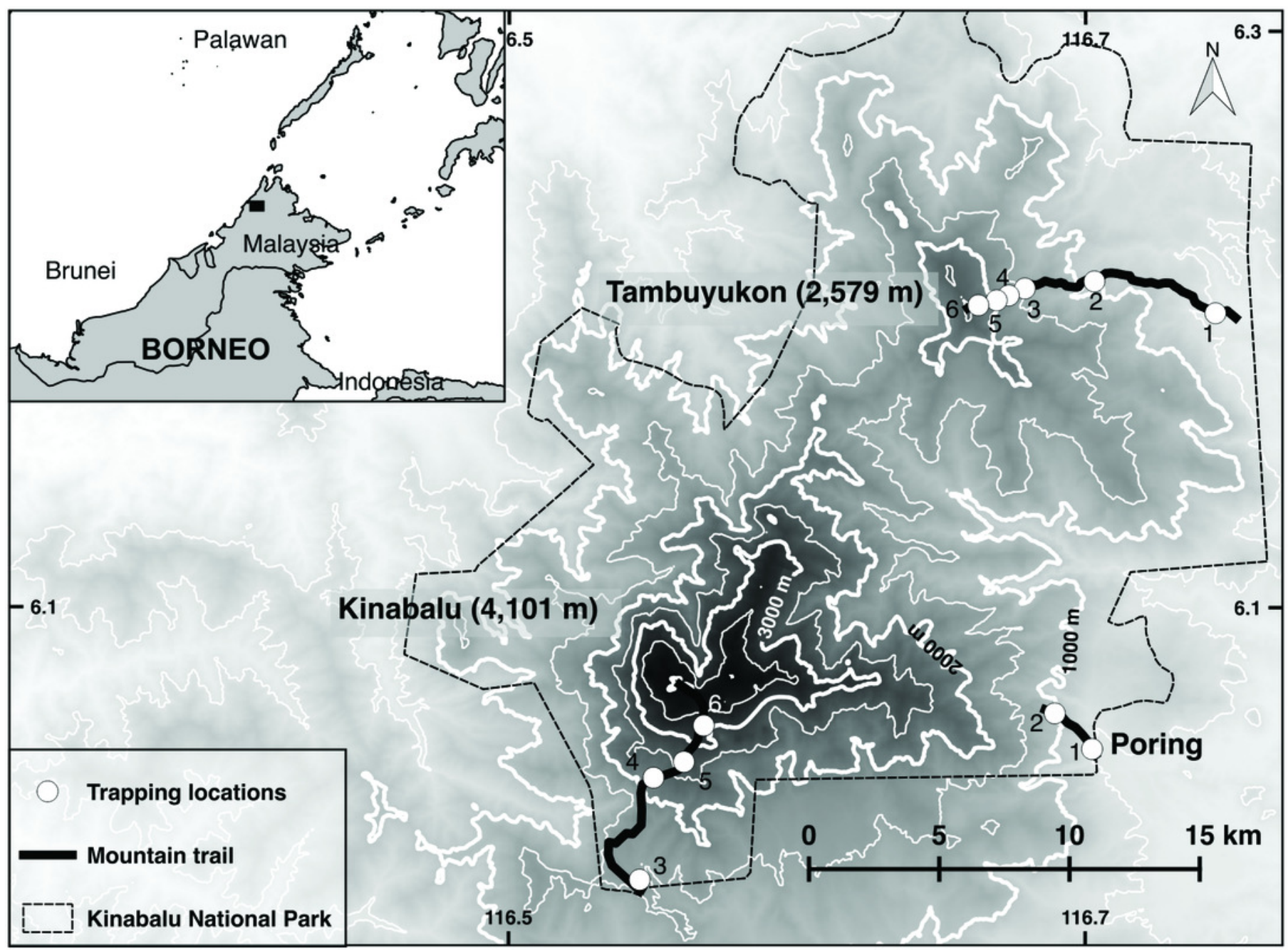


Figure 2

Species distribution across elevations.

Species distribution across elevations. Our two field surveys are represented by circles (Mt. Kinabalu), and triangles (Mt. Tambuyukon), together with a previous small mammal survey on Mt. Kinabalu (open squares; Nor, 2001). Endemic species are bolded. We have represented the vegetation levels as described in Kitayama (1992) for Mt. Kinabalu in greyscale in the background.

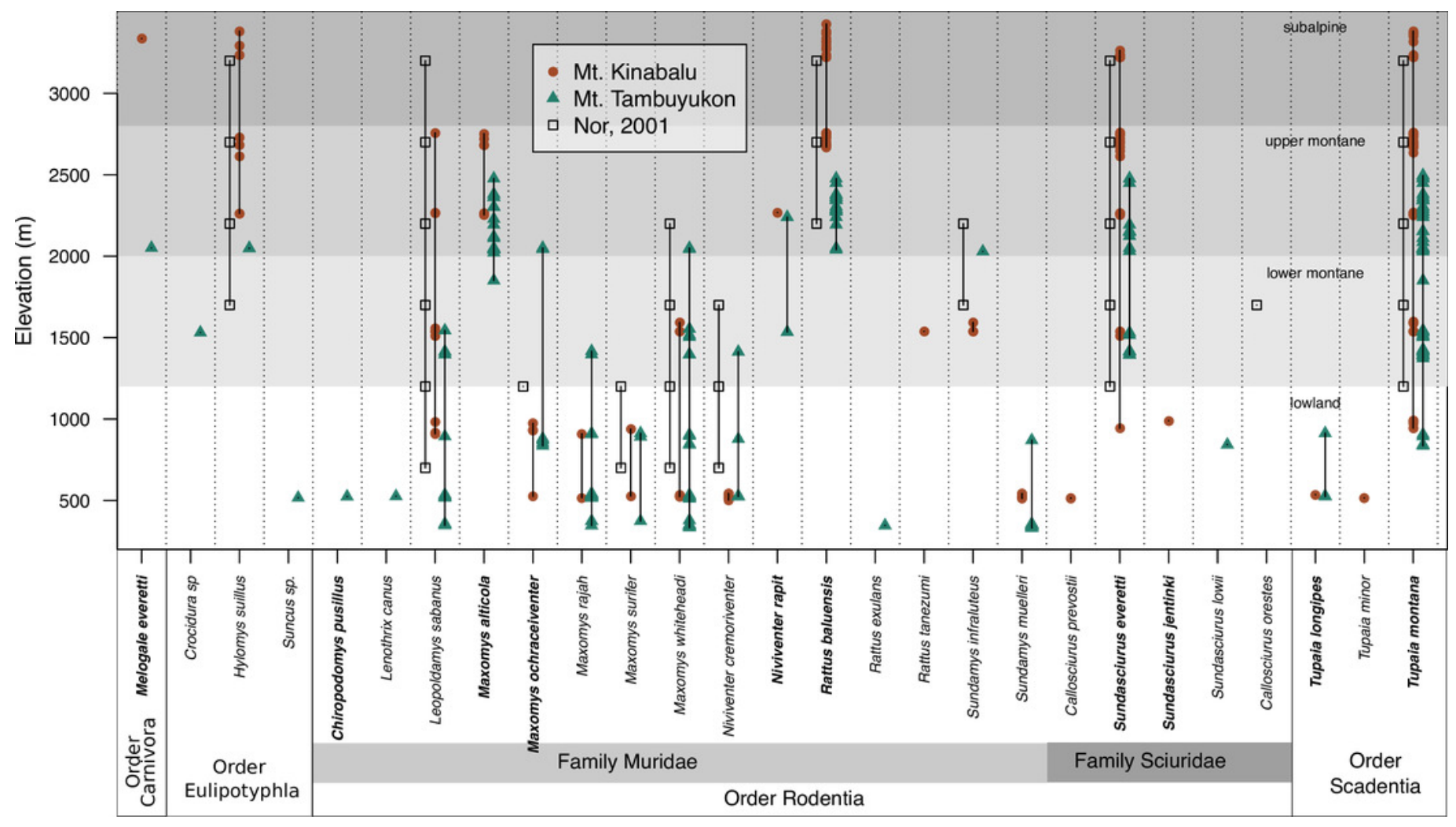




\section{Figure 3}

Diversity indices across elevations.

Diversity indices across elevations for Mt. Kinabalu (circles) and Mt. Tambuyukon (triangles) with loess regressions (Mt. Kinabalu, dashed line; Mt. Tambuyukon, pointed line). Shaded areas represent the $2.5 \%$ and $97.5 \%$ percentiles of the species richness for expectations under the MDE (Mt. Kinabalu, brown; Mt. Tambuyukon, green). Closed symbols in panel A are the fitted values of species richness corrected for autocorrelation.
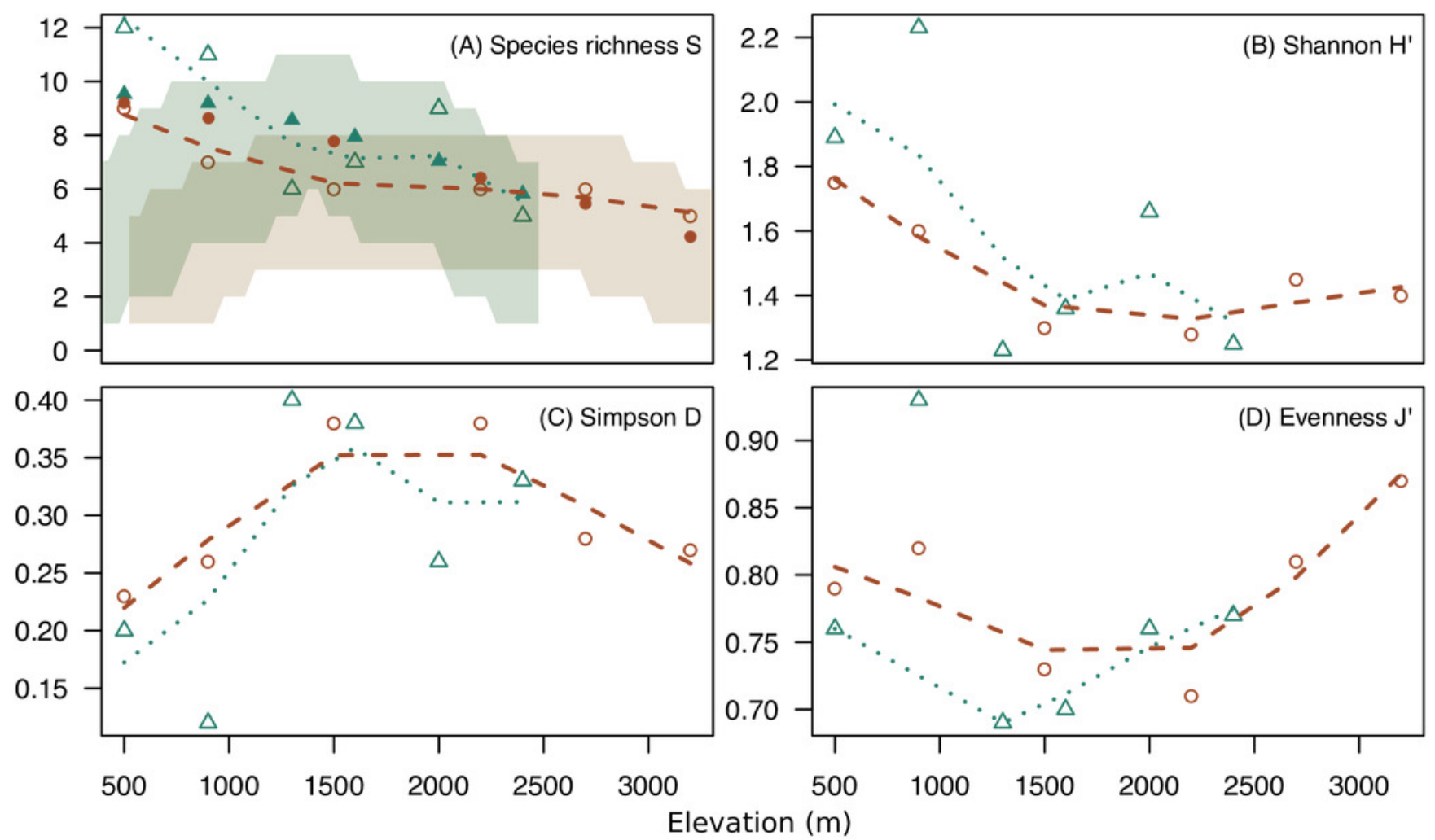
Figure 4

Endemism with elevation

Proportion of Bornean endemics (A) and proportion of catches belonging to Bornean endemics (B) across elevation. A confidence envelope for the observed values is represented as a shaded area from 1000 bootstrap replicates.
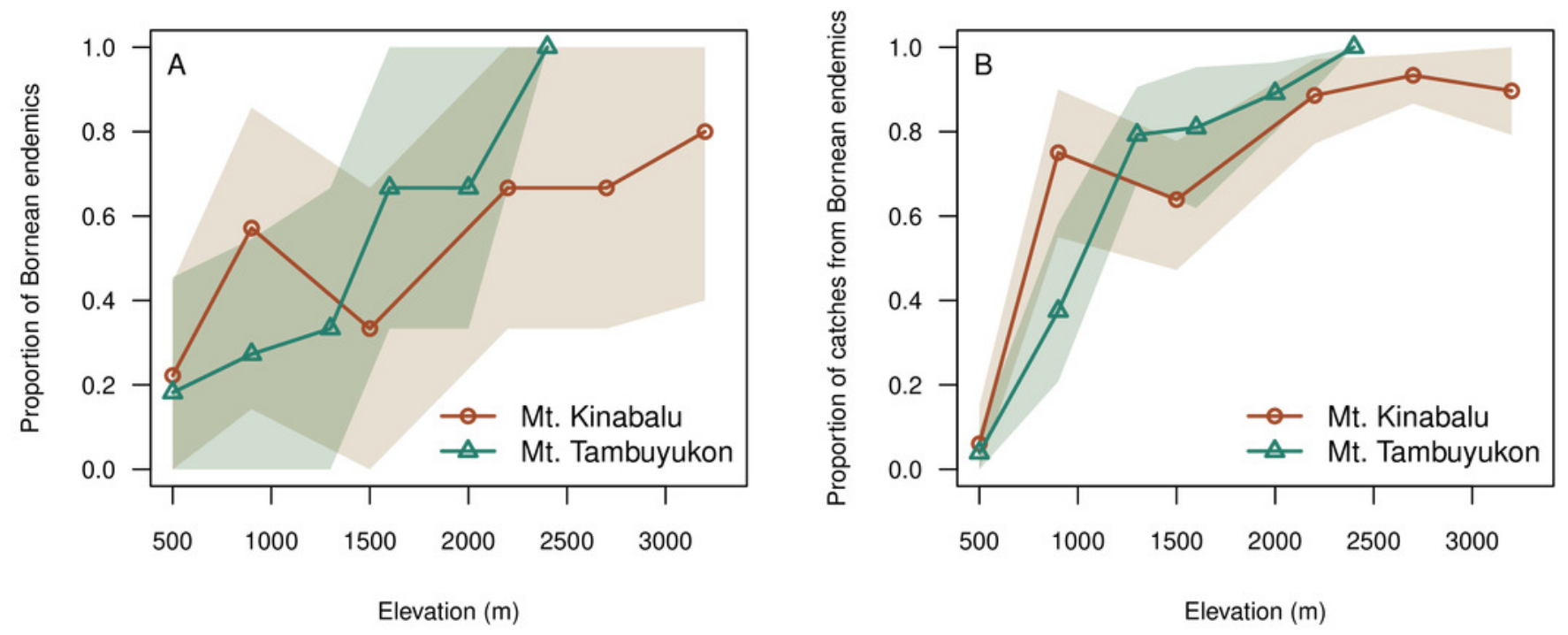
Figure 5

Beta diversity with and without endemics

Sorensen dissimilarity $\left(\mathrm{B}_{\mathrm{SOR}}\right)$ decomposed in it nestedness $\left(\mathrm{B}_{\mathrm{SNE}}\right)$ and turnover $\left(\mathrm{B}_{\mathrm{SIM}}\right)$ components, for Mt. Kinabalu and Mt. Tambuyukon (left/right depiction in set of data points, respectively). Solid horizontal lines represent the observed values, while the dotted horizontal lines are the estimated beta diversity measures after removing endemic species from the matrix $\left(B_{\text {SIM-end }}, B_{\text {SNE-end }}\right.$ and $\left.B_{\text {SOR-end }}\right)$. The random expectations for $B_{\text {SIM-end }}, B_{\text {SNE-end }}$ and $B_{\text {SOR-end }}$ are represented from the dotted cloud with 5,000 permuted values (see main text), together with their corresponding $2.5 \%$ and $97.5 \%$ percentiles (vertical grey bar).

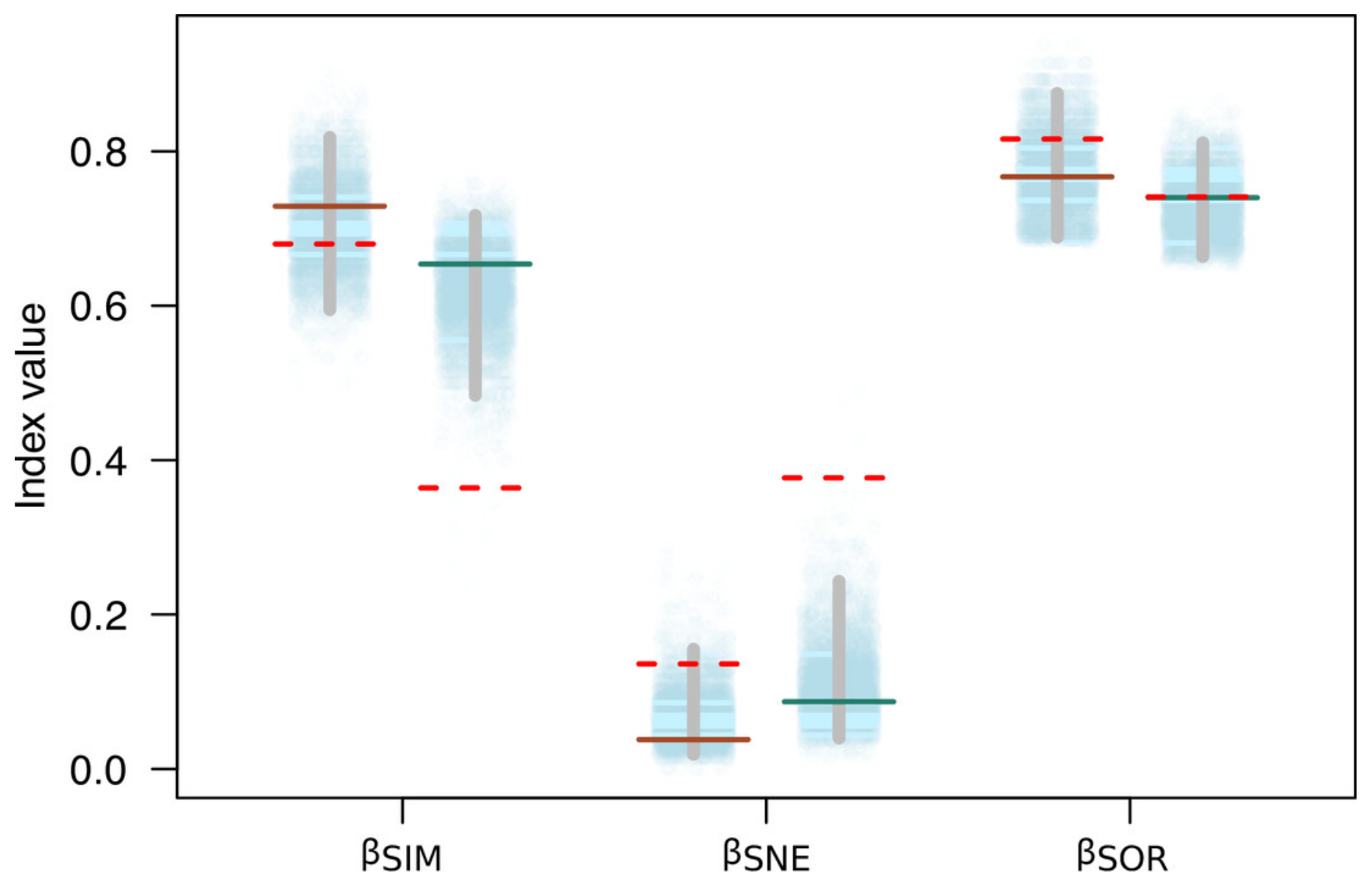

